Tourism in Analysis

DOI: http://dx.doi.org/10.11606/issn.1984-4867.v27i3p596-623

\title{
Turismo e campesinato na cidade de Colombo, PR, Brasil: (co)existência marcada por tempos diferenciados
}

\author{
Tourism and peasantry in the city of Colombo, PR, Brazil: \\ (co)existence marked by different times
}

\author{
Turismo y campesinado en la ciudad de Colombo, PR, Brasil: \\ coexistencia marcada por tiempos diferentes
}

Maria Jaqueline Elicher ${ }^{1}$
Telma Bittencourt Bassetti ${ }^{2}$

\section{Resumo}

Neste trabalho consideramos, de um lado, o turismo enquanto atividade econômica assentado em um sistema de mercado capitalista cujo movimento é assinalado pelo tempo rápido que define as características do consumo do e no espaço. De outro lado, definimos o campesinato brasileiro a partir da unidade produtiva, a terra; mas também a partir de sua cultura e modo de vida, marcados por um tempo lento, em oposição a regras que marcam a sociedade de consumo de maneira geral. Assim, o objetivo principal foi discutir a participação camponesa no desenvolvimento do turismo que se realiza no campo, especificamente no chamado Circuito Italiano de Turismo Rural do município Colombo, no Paraná. Para responder a essa questão seguimos as orientações do método histórico dialético, a partir da perspectiva da análise do discurso presente em entrevistas realizadas com os camponeses. Dentre os resultados alcançados podemos auferir que há resistência desses camponeses em inserirem-se no Circuito, principalmente perante a perda de autonomia de seu modo de vida ocasionada por sua inserção mais profunda na lógica do empresariamento.

Palavras-chave: Turismo; Campesinato; Capitalismo; Resistência; Cultura.

\section{Abstract}

In this article we consider tourism as economic activity seated in a capitalist market system, whose movement is marked by quick time that defines characteristics of the space and consumption. On the other hand, we dedicated theoretical effort to set the Brazilian peasantry from the production unit, the land; but also from their culture and way of life, marked by a slow motion kind of life, opposed to the rules that represent the consumer society in general.

\footnotetext{
1 Doutora em Geografia na área de Desenvolvimento Territorial e Ambiental pela Universidade Federal Fluminense (UFF). Professora Adjunta do Departamento de Turismo e Patrimônio da Universidade Federal do Estado do Rio de Janeiro (UNIRIO). Rio de Janeiro, Rio de Janeiro, Brasil. E-mail: maria.elicher@unirio.br

2 Doutora em Geografia Humana na área de lazer praticado em espaço rural pela Universidade de São Paulo (USP). Professora Adjunta do Departamento de Turismo e Patrimônio da Universidade Federal do Estado do Rio de Janeiro (UNIRIO). Rio de Janeiro, Rio de Janeiro, Brasil. E-mail: E-mail: telmabbassetti@hotmail.com
} 
Thus, the main objective was to discuss the peasant participation in tourism development that takes place in the field, specifically the so-called Italian Circuit of Rural Tourism, in the city of Colombo, in Parana, Brazil. To answer this question we follow the guidelines of the historical dialectic method, from the perspective of discourse analysis present on interviews with farmers. Among the results achieved we can derive that there is resistance in these peasants to be inserted in the Circuit, especially because of the loss of autonomy of their way of life caused by its deeper integration into the entrepreneurship logic.

Keywords: Tourism; Peasantry; Capitalism; Resistance; Culture.

\section{Resumen}

En este trabajo consideramos, por un lado, el turismo como actividad económica asentada en un sistema de mercado capitalista cuyo movimiento marca el dinamismo que define las características de consumo y de espacio. Por otro, definimos al agricultor brasileño a partir de la unidad productiva, la tierra; más bien a partir de su cultura y forma de vida, caracterizada por una lentitud en el pasaje del tiempo, contrario a las reglas que marcan la sociedad de consumo de forma general. Por lo tanto, el principal objetivo fue discutir la participación campesina en el desarrollo turístico que tiene lugar en el campo, especialmente en el llamado Circuito Italiano de Turismo Rural, de la ciudad brasileña de Colombo, Paraná. Para ello, seguimos las directrices del método histórico dialéctico, a partir de la perspectiva de análisis del discurso, presente en las entrevistas con los agricultores. Entre los resultados obtenidos podemos deducir que hay una resistencia de estos agricultores a insertarse en el Circuito Italiano de Turismo Rural, principalmente debido a la pérdida de autonomía de su forma de vida debido a una más profunda inserción en la lógica empresarial.

Palabras clave: Turismo; Agricultor; Capitalismo; Resistencia; Cultura.

\section{Introdução}

O trabalho aqui proposto deriva das discussões provenientes do Grupo de Pesquisa Turismo, Espaço e Urbanidades (GPET) do Departamento de Turismo e Patrimônio da Universidade Federal do Estado do Rio de Janeiro (Unirio), cadastrado no Conselho Nacional de Desenvolvimento Científico e Tecnológico (CNPq).

O fio condutor do debate é o turismo enquanto atividade econômica, desenvolvido no campo, com o apoio de políticas públicas e, em meio a esse embate, com a presença do camponês. O turismo cada vez mais se afirma como atividade capitalista direcionada ao lazer, que, por sua vez, já não mais é aproveitado a partir do uso do tempo livre, mas, na sociedade de consumo, é condicionado ao fazer turismo. 
Neste trabalho defendemos a ideia de que o turismo só se realiza no campo a partir da (re) valorização da natureza, em nada associada à agricultura enquanto atividade produtiva, senão como paisagem que legitima esse espaço enquanto rural; somado à cultura camponesa, os quais, juntos, são transformados em simulacros para atender às necessidades de consumo dos turistas em empreendimentos turísticos.

Nosso objeto de pesquisa foi o Circuito Italiano de Turismo Rural (Citur), desenvolvido na área rural de Colombo, município do Paraná. Assim, tivemos por objetivo geral analisar em que medida o avanço do turismo no município de Colombo, com apoio de políticas públicas, se desenvolve com participação camponesa.

Para responder às questões propostas, seguimos as orientações de Martins (1996) sobre a contribuição de Lefebvre (1981) do método que integrou a história na perspectiva dialética materialista, a partir da perspectiva da análise do discurso, conforme Orlandi (2003), que teoriza como a linguagem é materializada na ideologia e como esta se manifesta na linguagem. As entrevistas foram realizadas em julho de 2009 com vinte camponeses de Colombo que estão localizados geograficamente próximos ao Citur que se desenvolve na cidade paranaense, mas que, no entanto, não participam do roteiro ali implantado. Os "sujeitos" entrevistados serão identificados com letras do alfabeto (por exemplo, "Sujeito A", "Sujeito B" etc.). Nosso recorte temporal é a implementação do turismo no local, que seu deu no ano de 1996. Entendemos que a realidade social deve ser compreendida a partir do reconhecimento de uma dupla complexidade social, horizontal e vertical, que "se manifesta com mais vigor na eleição do mundo rural como referência inicial mais rica nas implicações metodológicas, pois é o que encerra maior diversidade e maior tensão de tempos históricos e de relações sociais datadas" (MARTINS, 1996, p. 21). Considerando isso, investigamos os motivos pelos quais alguns camponeses em Colombo não participam do desenvolvimento do turismo. $\mathrm{O}$ esforço foi no sentido de analisar as datas, os tempos diferenciados; os elementos que compõem a cultura material e espiritual da vida cotidiana do camponês, cujo objetivo foi tornar descoberto o que em um primeiro momento se apresenta como contemporâneo e simultâneo: as tramas sociais inseridas em suas épocas específicas. 


\section{Algumas considerações sobre o turismo e o campesinato, suas relações e suas especificidades}

Não é por acaso que autores mais críticos em relação às práticas turísticas (CRUZ, 2001; CARLOS, 1999; entre outros) utilizam a ideia de simulacro de Jean Baudrillard (1991) para designar os espaços que sofreram o processo de turistificação. Enquanto o mundo moderno era organizado em torno da produção, o mundo pós-moderno é regulado pela simulação. Diferentemente da imitação ou do fingimento, casos em que a diferença entre produto e realidade se mantém, simulacros, televisões e a realidade virtual confundem realidade e ilusão. Nessa direção, Carlos (1999, p. 26) afirma que

a indústria do turismo transforma tudo o que toca em artificial, cria um mundo fictício e mistificado de lazer, ilusório, onde o espaço se transforma em cenário para o "espetáculo" para uma multidão amorfa mediante a criação de uma série de atividades que conduzem à passividade.

No campo não é diferente porque a prática acaba se desdobrando em reproduções de outros espaços; simulacros, para agradar a uma demanda crescente de consumidores ávidos pela busca da natureza perdida e a cultura ali contida. Sobre o que estamos dizendo, Carneiro (2002) afirma, em sua pesquisa de doutorado, que a noção de pluriatividade e multifuncionalidade "recuperam uma característica da agricultura camponesa: a agricultura como modo de vida (integrada ao conjunto da sociedade e ancorada em um território)". Segundo a autora, atualmente, "há uma busca por uma nova imagem de agricultor que não é mais a mesma do 'agricultor moderno' ou do ‘verdadeiro agricultor' de há 10 anos passados [...]. Hoje todo mundo quer ser camponês" (Ibid., 2002, p. 234).

Ao contrário do que se diz nas políticas públicas voltadas para o desenvolvimento do campo a partir do turismo, na prática, o turismo que se realiza nesse espaço nada tem de diferente do modelo hegemônico de turismo desenvolvido nas praias pelo consumo de sol e de mar, senão pela diferença do espaço. Assim, o modelo hegemônico de turismo que se realiza no campo prevê que as propriedades localizadas no campo, voltadas para a prática turística, nada têm de agrícola, a não ser o espaço natural do entorno - embora o camponês esteja inserido neste contexto mais como um símbolo de consumo no imaginário popular: o trabalhador com chapéu de palha que retira leite da vaca, colhe as verduras etc.; proletarizado nos empreendimentos turísticos. 
O elemento cultural relacionado à imigração italiana (como é o caso de Colombo, no Paraná), também se coloca como fator de atratividade, restringindo o turismo em espaço rural àqueles que são descendentes de imigrantes italianos. A busca dos citadinos pelo campo pode ser parte do que Martins (1975) chamou de "ideologia urbana" - claro que no sentido de configuração e consumo do campo a partir do lazer e práticas sociais realizadas no campo, segundo padrões urbanos. Carneiro (2002, p. 226) parece concordar com o que estamos dizendo quando afirma que,

observa-se, então, a elaboração de uma outra vertente de representações sociais sobre o rural, não mais sustentadas na sua desqualificação como atrasado, mas apoiadas na valorização positiva da natureza e do patrimônio cultural dos espaços rurais. Essa busca, por parte dos habitantes das cidades, de um contato mais frequente e próximo com a natureza, idealizada, estimula o turismo.

Esse ideal de que nos fala a autora acaba por subtrair do campo brasileiro sua realidade, o que inclui as dificuldades e impedimentos de acesso a terra e a própria dificuldade de manutenção da agricultura enquanto atividade produtiva. Trata-se da construção de simulacros, na medida em que os elementos culturais e atividades produtivas, a exemplo da agricultura, são apreendidos pelo mercado e transformados em mercadoria, em empreendimentos turísticos e ofertados aos turistas na qualidade de simulacros. Para exemplificar o que estamos falando, basta apontar os pesque-pagues, as fazendas-hotéis, os hotéis-fazendas etc. tão em voga; há pouco tempo ausentes de produção agrícola, mas ricos em signos que expressam a cultura camponesa. Esses equipamentos são considerados simulacros uma vez que são apreendidos pelo mercado e transformados em mercadorias a serem ofertadas aos turistas que frequentam o campo.

Antes de avançar, porém, é preciso considerar que turismo não é, somente, uma atividade econômica - prova disso são as políticas públicas para fomento dessa atividade tendo em vista a melhoria das condições de vida nos lugares onde ele se realiza. Assim, as políticas públicas para o fomento do turismo no campo, enquanto atividade alternativa de renda, são direcionadas aos agricultores familiares. Se, de um lado, os camponeses em Colombo (PR) não se reconhecem como camponeses, mas como agricultores familiares, deslocando o campesinato a uma categoria de análise acadêmica; de outro, a despeito desse não reconhecimento, eles são camponeses. Sendo assim, é preciso considerar que a ideia de agricultor familiar, sugerida nas políticas públicas de turismo no campo, está assentada 
em um debate mais profundo o qual diz respeito à existência ou não do campesinato no Brasil, o que justifica a utilização do conceito em nossas análises.

A questão sobre o avanço das atividades turísticas no campo, tendo em vista a participação dos camponeses, diz respeito a um descompasso entre ritmos de vida pautados em temporalidades diferenciadas. Sobre esse descompasso entre universos de vida e, portanto, maneiras diferenciadas de lidar com as situações da vida cotidiana, Martins (1996, p. 15) chama atenção para o fato de que "na realidade coexistem relações sociais que têm datas diferentes e que estão, portanto, numa relação de descompasso e desencontro. Nem todas as relações sociais têm a mesma origem". Isso implica dizer que os indivíduos encaram a vida de maneiras diferenciadas, variando conforme sua história familiar, cultural e de vida. Esse processo de socialização, que torna o olhar individual distinto sobre um mesmo fenômeno, não pode ser considerado melhor ou pior do que outro olhar sobre o mesmo fenômeno. Assim, a afirmativa supracitada por Martins (1996, p. 15) de maneira nenhuma sugere que o campesinato seja ou deva ser considerado como atrasado ou arcaico. Nas palavras de Paulino (2006, p. 285), "a racionalidade camponesa é outra, o que não significa que ela deva ser atirada na vala comum que costuma ter como referência a oposição moderno e arcaico". Ou ainda, que será suprimido a partir do avanço do capitalismo via processo inexorável de proletarização. Nesse embate, entre avanço do capitalismo e dominação decorrente desse mesmo avanço, está a cultura e a vida humana que são (re)criadas enquanto resistência a esse processo.

Nessa direção, sobre o campesinato, podemos ousar afirmar não somente sobre sua existência como resistência, mas também que ele existe a despeito e atrelado ao modo de produção capitalista, contraditoriamente. Não como existia aos moldes de um século atrás, mas dinâmico e (re)criado a partir de variáveis que ainda os definem enquanto classe e/ou grupo social. Sobre as sociedades ameaçadas de desaparecimento via avanço do capitalismo, Sahlins (1997, p. 52) comenta: “essas sociedades não estavam desaparecendo há um século atrás [...], elas ainda estão desaparecendo - e estarão sempre desaparecendo".

Defendemos que, isoladamente, a base familiar de produção não pode ser considerada como critério suficiente e único para definir o camponês enquanto camponês. Ao contrário, a definição do camponês agrupa um conjunto de variáveis que, articuladas entre si, nos ajudam a pensar e definir o campesinato dos dias atuais, revelando o que se quer discutir nesta seção. O título da seção deve se coadunar com tal proposta. 
Tourism in Analysis

A análise do espaço rural brasileiro não comporta uma homogeneidade no sentido de atribuir características camponesas ou capitalistas, mas os usos diferenciados, nesses territórios, entre camponeses e capitalistas, é que reforça uma heterogeneidade às vezes não percebida pelos analistas. Ao confundir as lutas que se dão entre camponeses e capitalistas no campo e encará-lo como homogêneo, pode-se cair no erro de aceitá-lo da maneira como ele nos é dado e vendido: como um campo homogêneo de capitalistas ou de camponeses.

O modo de vida camponês escapa à lógica capitalista e o turismo é uma atividade aos moldes capitalistas. Para que o camponês desenvolva essa atividade em sua propriedade seria necessário sua transformação de camponês para empresário capitalista. Ou, que esse turismo fosse desenvolvido e submetido ao modo de vida camponês e não o contrário, segundo critérios de valores de uso e não de valores de troca. Dito de outra maneira, a partir da valorização de seu modo de vida em uma relação de respeito a essa mesma vida e não à valorização que pretende o turismo, enquanto atividade econômica submetida ao sistema de mercado capitalista: a transformação de tudo em mercadoria, incluindo aí sua própria vida. Aí está o impasse e o desafio.

\section{Especificidades do campesinato no Brasil para um entendimento do modo de vida do camponês}

Entender a lógica de vida camponesa é fundamental para a compreensão de sua incompatibilidade com a lógica que opera o turismo enquanto atividade econômica, o que justifica uma explicação mais extensa sobre esses sujeitos sociais, tão passíveis dos mais variados julgamentos pela sociedade, seja criminalizando-os em suas lutas, seja explorando-os em seus trabalhos. Uma das grandes contribuições para pensarmos o campesinato no Brasil vem de José de Souza Martins. Trata-se de um autor que faz parte de uma geração que rompe com as análises positivistas ao mesmo tempo que coloca a sociologia num novo status, redimensionando seu papel de explicação e de intervenção no processo histórico. A preocupação de Martins sempre foi o desenvolvimento do Brasil e as transformações sociais decorrentes da maneira como esse desenvolvimento foi estabelecido. Como o processo de modernização do Brasil passa pelo campo, Martins acaba por dedicar a esse processo uma atenção maior em suas pesquisas, tendo em vista a desorganização dos modos de vida da população rural, sobretudo no que diz respeito a suas relações sociais e culturais como desdobramentos das alterações na organização das atividades econômicas no país. 
Tourism in Analysis

Em Lefebvre (1981), Martins descobre um marxismo despojado de dogmatismo, não um Marx datado e situado no tempo e na história, mas um Marx de sua própria época, engajado em produzir ideias ao mesmo tempo que vivia e se envolvia em uma prática de transformação da sociedade a partir dos processos de reprodução social. Um Marx de uma obra inacabada e, por isso, carente de uma continuidade teórica. Nessa direção, uma fonte de inspiração para interpretar os problemas e o desenvolvimento do capitalismo no Brasil sem se restringir às determinações econômicas.

A contribuição de Lefebvre a Martins vai mais longe. Martins (2008) defende que Lefebvre retorna a Marx, mais especificamente ao núcleo explicativo do processo histórico, o qual consiste na ideia de que a relação entre o homem e a natureza se dá pela maneira como o aquele atua sobre esta a fim de atender a suas necessidades, modificando a natureza e suas condições de vida, alterando, também, sua relação com ela. Nessa direção, o homem deixa de ser repetitivo e reativo; mas, desafiado a criar, ele remodela suas condições de vida e a si próprio, ao mesmo tempo que, constituindo-se como humano, humaniza-se. Para Martins (2008), Lefebvre descobre que essa tese ganha consistência em uma noção mal formulada na obra de Marx: a de formação econômico social.

Martins (2008, p. 100) argumenta que se trata de uma ideia que aparece apenas ocasionalmente na obra marxiana,

apenas indicada, para dar conta da sedimentação dos momentos da história da práxis. Essa noção já carrega consigo, na descoberta de Lefebvre, o intuito de datação das relações sociais, a indicação de que as relações sociais não são uniformes nem tem a mesma idade. Na realidade coexistem relações sociais que têm datas diferentes e que estão, portanto, numa relação de descompasso e desencontro. Nem todas as relações sociais têm a mesma origem. Todas sobrevivem de diferentes momentos e circunstâncias históricas.

Nessa direção, Martins (2008) argumenta que Marx utilizava essa noção, em um primeiro momento, como um recurso metafórico para apoiar uma concepção interpretativa. Martins lembra que Marx utilizava metáforas seguidamente para expressar suas ideias e, ainda, que muitas dessas metáforas foram fetichizadas por seus vulgarizadores e transformadas em conceitos. Nas palavras do autor, 
o mais notório deles, o de modo de produção, é utilizado pelo próprio Marx de modo elástico e, às vezes, impreciso. Quando se trata do modo de produção capitalista, ora refere-se ao processo de trabalho, ora ao processo de valorização, ora tem uma certa conotação antropológica, referindo-se a um modo de fazer, mais no sentido de um procedimento cultural do que no sentido de uma referência estrutural. (MARTINS, 2008, p. 100)

Para Martins (2008), o reencontro da noção de formação econômico social por Lefebvre tem amplas significações já que se trata de uma noção com duplo significado: metodológico e teórico. $\mathrm{O}$ autor argumenta que essa noção tanto designa um processo histórico, ou seja, a formação econômico-social capitalista quanto designa o conjunto do processo histórico. Para ele, "mais do que uma imprecisão, essa duplicidade nos remete ao princípio explicativo de totalidade e, ao mesmo tempo, de unidade do diverso" (Ibid., p. 101). Martins (2008) também chama atenção para o fato de que muitos vulgarizadores da obra de Marx entenderam que "o diverso dessa unidade é apenas o diferente e que os termos da contradição, portanto, são contemporâneos".

A noção de formação econômico-social retomada por Lefebvre no preciso sentido da coexistência dos tempos históricos e também no sentido de que nessa coexistência se encerra não o passado e o presente, mas também o futuro, o devir, possibilitou a Martins um olhar sobre o campo que ultrapassa o próprio campo - isso porque o campo não está isolado dos demais processos, antes, inserido na totalidade dos processos sociais e suas leis. Assim, uma análise do campo desprendida da noção de totalidade se coloca insuficiente e incompleta. O método dialético, proposto por Lefebvre e retomado diretamente da dialética de Marx, é que tem orientado os estudos de Martins sobre o campo no Brasil. Nessa direção, Martins considera a história do desenvolvimento do capitalismo no Brasil como sendo contraditória, inacabada e incompleta. É essa relação de coexistência entre tempos diferentes que fundamenta nossa hipótese: turismo e campesinato estão situados em tempos diferenciados, daí sua incompatibilidade (ou resistência) em sua relação.

Outra grande contribuição ao pensamento de Martins veio de Rosa Luxemburg. Martins descobriu, em Luxemburg (1985), uma referência teórica que deu a ele condição de entender e interpretar a problemática do Brasil, em uma perspectiva marxiana, em que a produção do capital se realiza como processo o qual engendra e reproduz relações sociais não capitalistas 
de produção. Atenta à expansão do capitalismo em termos globais, sua reprodução em escala ampliada e seus desdobramentos, Luxemburg (1969) defende a ideia, já em outro livro (1985), de que o desenvolvimento do capitalismo em última instância não resultará na supressão de modos não capitalistas de maneira a integrar países e modos distintos de produção. Para ela, quanto mais o capitalismo se aproxima do momento em que todo o globo se tornará capitalista, contraditoriamente, mais esse ritmo diminui na medida em que, ele mesmo, produz relações sociais não capitalistas de produção. Vejamos o porquê.

Luxemburg (1985) argumenta que a produção capitalista não está limitada à produção de mercadorias cujo objetivo principal seja a satisfação de necessidades de consumo, nem tampouco se trata de produção mercantil, mas de produção capitalista. Isso porque a produção capitalista não é uma produção voltada para a satisfação de necessidades, mas para a produção de valor, logo, de mais-valia. É preciso lembrar que as relações de valor dominam totalmente tanto o processo de produção quanto o de reprodução.

Para o que nos interessa aqui, a contribuição de Luxemburg (1985) às análises de Martins diz respeito ao fato de que a mais-valia está na reprodução ampliada do capital, enquanto, com base nas relações de produção não capitalistas, há produção ou acumulação de capital. Essa afirmativa aponta para o fato de que, segundo a autora, a acumulação capitalista depende dos meios de produção que são produzidos de modo não capitalista. Assim,

o capital não pode existir sem contar com a presença dos meios de produção e da força de trabalho de toda parte; para o desenvolvimento pleno de seu movimento de acumulação ele necessita de todas as riquezas naturais e da força de trabalho de todas as regiões do globo. Uma vez que de fato e em sua maioria estas se encontram ligadas às formas de produção pré-capitalistas - que constituem o meio histórico de acumulação do capital -, daí resulta a tendência incontida do capital de apossar-se de todas as terras e sociedades. (Ibid., p. 251)

Para a autora, o capital, para desenvolver-se, necessita de formas não capitalistas de produção. No entanto, isso não se dá aleatoriamente. As análises de Luxemburg (1985) caminham na direção de que o capital necessita de camadas sociais não capitalistas para incrementar a reprodução de mais-valia, necessitando dessas sociedades como fontes de aquisição de seus bens e como reservatório de força de trabalho para seu sistema salarial. Sendo assim, as formas de economia natural, cujas bases estão assentadas em uma produção que se destina à 
satisfação de suas próprias necessidades, em que as formas de produção de cunho econômico-natural estão fundamentadas no vínculo com os meios de produção e com a mão-de-obra, impossibilitam ao capital realizar tais objetivos.

Dessa forma, uma vez que o trabalho camponês estabelece como base de sua organização econômica a sujeição dos principais meios de produção, terra e força de trabalho, ao direito e à origem, o desdobramento dessa forma de economia cria sérias dificuldades às exigências do capital. É por isso que, conclui Luxemburg (1985, p. 254), “o capitalismo, onde quer que seja, procura sempre destruir a economia natural sob todas suas formas históricas com as quais pode vir a deparar-se: luta contra a escravatura, contra o feudalismo, contra o comunismo primitivo e contra a economia camponesa patriarcal".

Essa ideia permitiu a Martins sustentar a noção de que o mundo rural não aparece como impedimento ao desenvolvimento do capitalismo ou como um resíduo que tende a desaparecer, mas como um tempo e uma forma social que faz parte integrante do desenvolvimento do capitalismo no Brasil. Essa postura entra em choque direto com a visão marxista ortodoxa que pensa o campesinato inserido em um processo inexorável de desaparecimento via proletarização.

Martins utiliza a categoria de camponês para explicar o desenvolvimento capitalista do Brasil graças a um esforço de interpretação crítica da obra de Marx, o que significa a superação ou ampliação de algumas noções utilizadas pelo autor. Esse é o caso da categoria marxiana de produção e reprodução das relações sociais capitalistas. Essa categoria tem passado despercebida por grande parte dos produtores de conhecimento sobre o campo. Martins retoma essa noção a partir das leituras de Luxemburg (1985) e acaba por elaborar outra, a qual ele define como produção capitalista de relações sociais não capitalistas. Assim, turismo no campo enquanto atividade econômica capitalista se coloca em embate às relações sociais não capitalistas de produção representadas pelo campesinato, em alguns aspectos.

A partir dessa perspectiva teórica e metodológica, Martins recusa as simplificações próprias de autores que, nas décadas de 1950 e 1960, discutiam o caráter da sociedade brasileira. Isso porque, em sua perspectiva analítica, a noção de relações sociais pré-capitalistas pressupõe uma sucessão histórica, enquanto as relações sociais não capitalistas constituem formas de relações sociais que não têm a temporalidade das relações pré-capitalistas e que são contemporâneas das relações sociais capitalistas de produção produzidas pelo próprio desenvolvimento e expansão do capital. 
Martins (2004) pensa a realidade social do campo brasileiro a partir da hipótese de que o capitalismo, em sua expansão, não só redefine antigas relações, subordinando-as à reprodução do capital, mas também engendra relações não capitalistas igual e contraditoriamente necessárias a essa reprodução. Segundo Martins (2004) o regime de trabalho conhecido como colonato não pode ser considerado um regime assalariado, já que, no processo capitalista, o salário em dinheiro é a única forma de remuneração da força de trabalho.

Para o autor, o colonato se caracterizou pela combinação de três elementos, a saber: "um pagamento fixo pelo trato do cafezal, um pagamento proporcional pela quantidade de café colhido e produção direta de alimentos como meio de vida e como excedentes comercializáveis pelo próprio trabalhador" (Ibid., p. 19). Esses três elementos supracitados somados ao fato de que o colono não era um trabalhador individual, mas um trabalhador familiar cujo resultado desse trabalho era a produção direta de seus meios de vida é que impossibilitam definir essas relações como sendo relações capitalistas de produção. Martins (2004, p. 19) conclui sua ideia argumentando que

a prévia mercantilização de todos os fatores envolvidos nessas relações, mediante o que o salário não pode ser um salário aritmético, isto é, disfarçado, mas deve ser salário em dinheiro para que os meios de vida necessários à produção da força de trabalho sejam adquiridos pela mediação do mercado, é condição para que as relações de produção se determinem como relações capitalistas de produção. Tal condição, porém, não se dá nesse caso. O salário aritmético é um salário que entra na cabeça do capitalista, mas que não entra no bolso do trabalhador, não produz uma relação social.

Do desdobramento dessa ideia estão outras ideias construídas pelo autor e que ajudam a pensar o campesinato no Brasil, são elas: ideologia urbana (1975); terra de trabalho e terra de negócio (1980); sujeição da renda da terra ao capital (1980), entre outras.

Embora as relações de trabalho do camponês e a unidade de produção sejam critérios importantes para a definição do camponês enquanto categorias de análise, entendemos que os aspectos culturais, no plano social, bem como os desdobramentos desses processos para reprodução familiar sejam critérios também importantes para sua definição. Assim, os elementos culturais relacionados às trocas matrimoniais, às transações de terra entre vizinhos para manutenção da família, à divisão do trabalho familiar (delegando ao homem e à mulher 
papéis bem definidos) e ao conjunto de regras sociais próprias que regem a vida cotidiana se colocam, também, como critérios importantes para definição do camponês. Essa definição é importante na medida em que tem como objetivo se colocar temporalmente em oposição ao turismo, enquanto atividade econômica com uma lógica de operacionalização própria.

Sobre o que estamos dizendo, Ellen Woortmann (1995, p. 16), na introdução de seu trabalho referente a sua tese de doutorado, justifica suas escolhas metodológicas a partir do fato de que "no Brasil, a ênfase de muitas análises sobre o campesinato recaiu sobre o grupo doméstico como unidade de produção e de consumo, isto é, a reprodução, no tempo, da condição camponesa". Assim, a proposta da autora caminha na direção de privilegiar as relações que interligam grupos domésticos, que ela define como famílias, a partir de seus valores em detrimento de sua classificação enquanto unidades produtoras ou consumidoras. Isso porque, na perspectiva da autora,

Chayanov considerava a família como um conjunto de produtores e de consumidores, quer dizer, uma unidade de força de trabalho e de consumo centrada num casal e seus filhos [...]. A família é vista por ele como um grupo doméstico, isto é, desde uma ótica econômica, e não como um valor cultural - outra dimensão básica para entender o campesinato. (Ibid., p. 30)

A autora segue argumentando que a terra, no olhar de Alexander Chayanov, constitui elemento de produção, independente de seu conteúdo ideológico. Woortmann (1995) defende a ideia de que a família é uma unidade econômica ocupada em reproduzir seus fatores de produção. Nessa direção, para a autora, Chayanov vê o grupo doméstico como se não existisse a família - o que não significa dizer que a autora não reconheça a contribuição de Chayanov para o estudo do campesinato, uma vez que ele utilizou as relações de trabalho no grupo doméstico e, a partir delas, elaborou as leis da economia camponesa em oposição à economia de produção capitalista. No entanto, as relações de família para Chayanov são vistas apenas como relações de trabalho.

Ellen Woortmann está preocupada com as relações de produção social da família para além da produção econômica da família. A autora está investigando a reprodução camponesa, em suas gerações, a partir das relações de parentesco - daí a importância das relações de casamento para a manutenção da terra e, subsequentemente, da família. Para ela, a terra é vista como 
Tourism in Analysis

patrimônio, isto é, como valor moral, carregada de valores simbólicos para além de fator de produção, apenas. Isso porque não se trata de uma mercadoria plena, já que ela é patrimônio da família, o que justifica a preocupação da autora em investigar as relações de casamento e herança dado que elas têm como finalidade assegurar a reprodução da família tendo como pressuposto a permanência da terra nas mãos da família.

Entendemos dessa maneira que a cultura, o ethos, enquanto modo de agir, de proceder, se coloca como categoria analítica importante na definição do campesinato. A exemplo do que estamos dizendo - aproximando-se do que Martins (1973) define como comunidade utópica em que as bases das relações sociais estão pautadas em outras dimensões para além dos interesses individualistas - está o descompasso entre a herança e o acerto, aquilo que Moura (1978) chamou de "força da lei”, de um lado, e "consideração", de outro. Nas palavras do autor,

\footnotetext{
para os camponeses, "herança" são aquelas regras inarredáveis do Código Civil acionadas quando da morte de um membro da família de orientação, o pai ou a mãe, e que se iniciam com a comunicação à comarca, pelo par sobrevivente, de tal acontecimento, atraindo em seguida a presença de avaliadores de seus bens. Todas as demais, analisadas (pela autora) como regras de herança da terra de tipo vertical ou horizontal, não obtêm esta denominação (herança) e são chamadas de "acertos", "arranjos" ou ainda "presentes' ou, [...] fruto de manifestações de "preferência", "união" ou "consideração". Não estão relacionadas seja à ideia de que um membro da velha geração deixa algo para os da nova geração em função de sua morte ou ante a perspectiva dela. (Ibid., p. 49)
}

Ainda pensando na cultura enquanto categoria de análise para além da unidade de produção, como instrumento importante para expressar o modo de vida camponês, faremos uso do que Klaas Woortmann (1990) chamou de campesinidade, cuja definição se dá a partir de um aspecto qualitativo, como um elemento de identificação, um conjunto de valores éticos. Nessa perspectiva, a terra, por exemplo,

não é vista como um objeto de trabalho, mas como expressão de uma moralidade; não em sua exterioridade como fator de produção, mas como algo pensado e representado no contexto de valorações éticas. Vê-se a terra, não como natureza sobre a qual se projeta o trabalho de um grupo doméstico, mas como patrimônio da família, sobre a qual se faz o trabalho que constrói a família enquanto valor. Como patrimônio, ou como dádiva de Deus, a terra não é simples coisa ou mercadoria. (Ibid., p. 13) 
O autor está se referindo a valores sociais, não do valor trabalho, antes, do trabalho enquanto valor ético. Esse olhar, segundo o autor, se afasta, portanto, da tendência economicista que vê o campesinato como um modo de produção com sua lógica própria ou como determinações impostas pela lógica do capital, afinal, nas palavras do autor, "se o mercado domina o campesinato, ele não o organiza" (Ibid., p. 12).

Se, de um lado, a economia for tratada isoladamente, ela não pode ser considerada determinante para definição do camponês. De outro lado, a cultura, por sua vez, isolada, também não é suficiente para definirmos o camponês enquanto camponês. Isso significa que essas duas categorias de análise, juntas, modificam uma e outra e são modificadas por uma e outra. Nessa direção, há situações específicas em que uma ou outra categoria, economia e/ou cultura, sobressaem de tal maneira, a ponto de determinar o sujeito como camponês ou não. A oposição estaria entre a comunidade camponesa e a sociedade moderna, na medida em que a sociedade moderna é individualizada e voltada para o mercado. Dito de outra maneira, é como se a oposição estivesse no campo da ordem moral versus ordem econômica. Evidente que na sociedade moderna as três categorias supracitadas existem, contudo, elas podem existir separadas uma das outras. Assim, a terra não é pensada em função da família e do trabalho, mas em função de si mesma, como uma coisa ou, ainda, como uma mercadoria. A família também é pensada em si mesma, sem relação com o trabalho ou com a terra, de igual maneira o trabalho, pode ser pensado como uma abstração (Ibid., 1990).

O caráter familiar do trabalho é um assunto que consideramos importante discutir. Apesar das muitas variáveis existentes para definição do camponês enquanto camponês, o caráter familiar do trabalho se coloca como elemento central de uma lógica econômica própria das práticas sociais camponesas. O estudo clássico de Chayanov (1974) embasou no Brasil um conjunto de pesquisas que se propuseram a analisar essa especificidade. Para Woortmann (1990), entretanto, a tradição marxista que percebe a pequena produção como determinada pelo capital tampouco deixou de enfatizar esse caráter familiar, tido como a condição mestra de subordinação ao capital. Nas palavras do autor,

não raro o trabalho familiar é visto em oposição ao trabalho assalariado, ainda que, objetivamente, contudo, não haja uma contradição necessária entre ambos. Subjetivamente, contudo, observa-se uma oposição, no contexto de 
uma concepção camponesa do trabalho. Mas em boa medida, tudo depende do lugar onde se dá o trabalho e de quem se relaciona através dele. (Ibid., p. 25)

Em unidades camponesas, o uso do trabalho assalariado se dá quase que, majoritariamente, em caráter temporário, enquanto o trabalho permanente é fornecido pelo grupo doméstico. Entretanto, as experiências etnográficas realizadas pelo autor indicam que, "longe de opor ao trabalho doméstico e ao trabalho, como categoria indissociável da família, o uso do trabalho assalariado é a condição mesma de realização desta ultima" (Ibid., p. 26). Isso porque a contratação da mão de obra assalariada se dá nos momentos de pico do ciclo agrícola, uma vez que o volume de trabalho a ser realizado nesse momento determinará o trabalho realizado durante todo o ciclo. Nesse sentido, a contratação dos trabalhadores temporários implicará a viabilização da atividade dos membros da família e não a ela se opor. Na visão de Woortmann (1990, p. 26), “o uso do trabalho assalariado, nas situações onde ocorre, é condição para que se realizem o pai de família e a hierarquia familiar, isto é, o valor-família, e não apenas a produção doméstica". É relevante também citar a importância relacionada aos saberes camponeses. Para Woortmann (1990) o fato de negligenciar o saber dos mais velhos dentro de uma família camponesa implica subverter a ordem familiar. Isso porque, na sociedade moderna, o velho é desprezado pela impossibilidade de se tornar força de trabalho, grosso modo, o velho é descartado por sua inutilidade perante a multidão de novidade posta à venda nessas sociedades, o que se estende às relações sociais no plano do indivíduo. Essa transferência de valores para a comunidade camponesa, gerada pela lógica do capital, é considerada uma afronta e uma desonra para a família camponesa: "é por ser dono do saber que ele é dono do sítio e pai da família. Ele não é velho, mas um sábio" (WOORTMANN, 1990, p. 48). Se de um lado o camponês é definido a partir de sua relação com a terra, seja por meio da agricultura enquanto atividade econômica produtiva ou como patrimônio - isto é, como valor moral -, de outro lado, a cultura, enquanto modo de vida, associada a terra, também não pode ser negligenciada enquanto categoria de análise importante para definir o camponês. Assim, terra e cultura, juntas, estão diretamente relacionadas ao camponês e legitimam sua existência. 
Tourism in Analysis

\section{Turismo e campesinato, um difícil diálogo}

As análises que se seguem são resultado de pesquisa feita com camponeses residentes em Colombo, cidade turística localizada na Grande Curitiba (PR). Trata-se de um município localizado próximo à cidade de Curitiba, formado, em sua parte agrícola, por imigrantes italianos que têm na olericultura, na produção de uvas e vinhos e no turismo, dentre outras, suas atividades econômicas principais. Ali o turismo se desenvolve com apoio de políticas públicas desde o ano de $1996^{3}$, dentre as quais podemos citar a Política Nacional de Municipalização do Turismo (PNMT) e o Plano Nacional de Turismo, entre outras específicas do turismo desenvolvido no campo.

O agroturismo é uma das poucas atividades que pode ser usada como aporte ao desenvolvimento do campo pelo turismo com participação camponesa. Isso porque em sua base conceitual está a ideia de que o visitante pode interagir com as atividades realizadas no interior da propriedade, teoricamente, sem interromper sua rotina de trabalho. Nesse caso, há uma adequação da propriedade para receber o turista, mas não a reinvenção de suas atividades (ou ainda, a realização de atividades descoladas do contexto no qual ela está inserida, nesse caso, o campo). Queremos destacar que Colombo, de certa forma, copia o modelo de turismo implantado no interior do Espírito Santo, à despeito de suas especificidades.

O trabalho de campo em Colombo trouxe à baila um elemento que não estávamos esperando: os camponeses não inseridos no Citur da cidade, embora localizados próximos ao Circuito, não o estão porque não querem estar. Se, de um lado, no plano econômico, é necessário que o camponês tenha recursos financeiros disponíveis para modificar sua propriedade de maneira a atender aos critérios de padronização de suas propriedades ao turismo, de outro lado, a cultura, enquanto categoria analítica, se impôs, mais do que a economia, como elemento limitador da possibilidade do camponês tornar sua propriedade, além de agrícola, turística. A questão vai se tornando mais complexa à medida que fomos percebendo que a agricultura (em Colombo a produção agrícola, em sua maioria, diz respeito à olericultura), enquanto atividade econômica desenvolvida pelos camponeses entrevistados, em sua perspectiva, é

\footnotetext{
3 Outros projetos foram implantados concomitantemente, tais como os Projetos Regionais de Turismo. Segundo Silveira (2003), esses projetos, agrupados com vários outros projetos e ações, fizeram parte da política de turismo no âmbito estadual, cujas propostas e ações objetivavam a implementação de atividades voltadas para a exploração do turismo rural, do ecoturismo e do turismo cultural na Região Metropolitana de Curitiba (RMC).
} 
incompatível com a atividade turística. Isso porque a atividade turística exige uma disponibilidade de tempo do agricultor que nem sempre existe, posto que a atividade agrícola já lhe toma bastante tempo. A exceção está na produção da uva, que não está acessível ao turista, mas limitada ao olhar. Essa exceção se justifica na medida em que a visitação limitada ao olhar não atrapalha as atividades de cuidado com a lavoura, nesse caso, da uva. A manutenção de sua autonomia em relação a seu próprio tempo e vida cotidiana e o cuidado com a lavoura, juntos, falam sempre mais alto do que a possibilidade de receber turistas.

É evidente que existem movimentos no campo no sentido de organizar as propriedades para receber turistas. No entanto, são passíveis de estudos. O que está em questão aqui é o embate entre o modo de vida camponês e a lógica em que o turismo, enquanto atividade econômica, opera. Esse embate se torna um impedimento à inserção do camponês no processo de desenvolvimento do turismo no campo com participação de políticas públicas. Isso porque ele, o camponês, é o sujeito social, o objetivo a ser alcançado por esse suposto desenvolvimento. Alguns camponeses, quando questionados sobre o Circuito Turístico Italiano Rural em Colombo, demonstraram sequer conhecer o Circuito. Esse desconhecimento aponta para uma vida que se realiza a despeito do turismo e das relações sociais decorrentes dessa atividade. Mesmo assim, quando insistimos na pergunta, questionando-o mais veemente sobre a possibilidade de ele receber turistas, a resposta vem, em um primeiro momento, vacilante, mas, num segundo momento, decisiva: “acho que não, porque ... incomoda!” (Sujeito A).

Esse incômodo, mencionado pelo camponês (Sujeito A) diz respeito, sobretudo, a atrapalhar o trabalho realizado na lavoura. Outro camponês, entrevistado também, não tinha ouvido falar do Citur em Colombo. Quando perguntamos a ele se ele tinha interesse em receber turistas em sua propriedade, a resposta foi firme e não deixou dúvidas sobre sua opinião em relação ao turismo: "Tem nada que envolver isso aí. Ocupar e largar as verduras!" (Sujeito A).

A dedicação ao trabalho na lavoura e a consciência de como esse trabalho é pesado e demanda responsabilidade e cuidados frequentes justificam em quase todos os entrevistados sua escolha pelo trabalho na lavoura em detrimento do turismo. Isso porque, para esses camponeses, não há como conciliar as duas coisas: agricultura e turismo. Durante nossa entrevista com uma senhora que foi mais uma conversa do que propriamente uma entrevista -, depois de ela dizer em vários momentos que não gostaria de receber turistas e de contarmos a ela 
Tourism in Analysis

que outros agricultores entrevistados também não o queriam porque eles acham que o turismo atrapalha o trabalho na lavoura, ela disse, enfaticamente:

Exatamente! Atrapalha, porque se você se dedicar ao Circuito é ao Circuito. Você não pode se dedicar à agricultura. Não tem condições. Ou a agricultura ou o Circuito. E ele [referindo-se ao marido] gosta disso aí [referindo-se a agricultura]. (Sujeito B)

A fala dessa camponesa nos reporta dois fatores: o primeiro diz respeito ao trabalho árduo para manutenção da lavoura; o segundo, ao prazer de trabalhar nessa mesma lavoura. $\mathrm{O}$ amor e a dedicação necessários ao trabalho agrícola, e, claro, aos frutos decorrentes desse trabalho, os quais para o camponês diz respeito à manutenção de sua família, é o alimento necessário ao trabalho cotidiano. Contudo, ao mesmo tempo que o bem-estar da família está acima de qualquer sacrifício, contraditoriamente, esse esforço e tempo dedicados ao trabalho são limitados pela satisfação desse bem-estar, o qual inclui a realização da vida, sem pretensões maiores que possam ir além de sua manutenção. Insistimos com essa camponesa sobre a possibilidade de ela receber turistas em sua propriedade. E, como parte de nossa pergunta, falamos sobre os benefícios econômicos que o turismo poderia gerar pra ela, e assim ela nos respondeu:

É, exatamente. Mas minha filha, você tem que trabalhar o triplo! [...] Porque eu sei, já eu não tenho mais condições de trabalhar assim. Eu fiz uma cirurgia de coluna. Eu tava na minha horta hoje. Que eu gosto da minha hortinha, né. Ai. Não vai. Não posso mais trabalhar! E se vocêfaz isso aqui. É em vidro, é em vidro, é envidrar. É preparar, atender as pessoas, né? Nos finais de semana. E durante a semana você tem que deixar preparado para o fim de semana. Meu marido não quer! Ele não quer! Ele gosta de liberdade com tudo que tem no domingo, né?! (Sujeito B)

Fizemos a mesma pergunta para outra camponesa entrevistada, e a resposta dela confirmou o que dissemos anteriormente sobre dedicar-se tanto ao trabalho que a implicação direta desse excesso, para além da agricultura, estaria na redução de sua autonomia e tempo livre disponível para si mesmo e para a família. Em suas palavras: 
Tourism in Analysis

Me diz uma coisa, vai ganhar mais dinheiro pra quê? Se tendo um pouco pra você ter saúde e precisa se alimentar, e ter um pouco pra quando a gente precisa, eu acho que, sei lá, é que nem eu digo pro meu marido, de fome nós não vamos morrer. E gananciar mais não adianta! (Sujeito C)

Ainda sobre o turismo atrapalhar a produção agrícola, entrevistamos outro camponês, dedicado à produção de uva e vinho, além de olericultura. Trata-se de uma pequena propriedade de base familiar que cultiva a uva e produz o vinho artesanalmente. Dos integrantes da família, apenas ele e seu pai trabalham na lavoura (olericultura), no cultivo da uva e na produção artesanal do vinho. No momento da entrevista sua mãe estava presente. Sua família tem uma pequena vinícola localizada próxima de uma propriedade agrícola cuja produção de vinho a caracterizava como sendo turística, e, portanto, inserida no circuito turístico da cidade. Contudo, essa vinícola não faz parte do Citur. Quando questionamos os motivos pelos quais eles não estavam inseridos no Circuito, já que estavam tão próximos do roteiro e produziam vinho, a primeira resposta foi:

Ai, dá muita dor de cabeça! E aí, nós somos em pouca gente, né? A gente vive muito ocupado, né? Ai chega fim de semana que vem um monte de gente, né? A gente não vive só do vinho, né, nós temos agricultura, eu mexo com caminhão. E a gente não tá sempre ali pra atender e o Circuito tinha que ter, tipo, ter disponibilidade, né, estar direto ali. (Sujeito $\mathrm{D}$ )

A preocupação desse camponês em relação à perda de sua autonomia, sobretudo no que diz respeito a seu tempo livre do trabalho, mais especificamente nos finais de semana, que é exatamente o tempo em que o turismo se realiza, é, também, uma preocupação que se apresenta em outros camponeses entrevistados.

Outra questão que surgiu durante a realização das entrevistas foi o descompasso entre os diferentes significados que a agricultura tem para os turistas e para os camponeses. Para os turistas, a agricultura é a essência do turismo que se realiza no espaço rural, que compõe a paisagem e que legitima, no imaginário do citadino, a diferença entre campo e cidade, mesmo que essa agricultura, em um primeiro momento, não seja, de maneira direta, consumida pelos turistas. Para os camponeses, por sua vez, a agricultura é uma atividade econômica e produtiva, permeada de valores, os quais, combinados, norteiam toda sua vida. Assim, para os camponeses, não há nada em seu trabalho (o cuidado com a lavoura) que seja considerado 
Tourism in Analysis

atrativo, do ponto de vista turístico, que seja passível de ser visitado. Foi o que um camponês me perguntou quando indagado sobre a possibilidade de receber turistas: "fazer o quê, mas aqui, e fazer o quê aqui, num (?)..." (Sujeito F).

Nessa mesma direção, o pai desse camponês, que estava perto de nós enquanto conversávamos, entrou na conversa e foi, imediatamente, se posicionando em relação ao turismo. Para ele, o turismo lhe era apresentado como algo totalmente estranho a suas práticas cotidianas, tanto que soava como uma ameaça. Assim, aquilo que é estranho e, portanto, desconhecido, não pode, de maneira nenhuma, ser recebido em sua casa. Nas palavras dele:

Turismo dá muito problema! Em Imbuial, três, quatro anos atrás, chegaram muitos turistas lá. De repente começaram se fingir de turistas e limpar com as casas do pessoal. É problema, né?! [...] Teve casa que eles chegavam com o caminhão e tiravam tudo que tinha dentro de casa, mudança inteira. Pode acontecer uma coisa dessas? Só tinha a ver com turismo porque depois que eles começaram a receber turistas. Isso é problema, né?! Vem turista bom, mas depois tem aquele que se finge de turista, entendeu? (Sujeito G)

É preciso considerar que em todo nosso trabalho de campo não ouvimos nada sobre esse fato, nem por parte da Secretaria de Turismo de Colombo, nem por parte dos camponeses entrevistados. É claro que não estamos dizendo que seja invenção por parte dele. Entretanto, pode ser que tenha havido mesmo um assalto e que esse acontecimento tenha sido atribuído equivocadamente aos turistas. Dando sequência a nossa argumentação, as palavras desse camponês expressam não só um receio em receber os turistas, tendo em vista que para ele o turista é um sujeito desconhecido que pode, inclusive, lhe fazer o mal; como também apontam para o fato de que, associado a essa ideia, não há nada em sua propriedade que possa ser considerado atrativo turístico. Assim, quando perguntamos o que ele achava da ideia de receber turistas em sua casa, mesmo que individualmente, em vez de ônibus, sua resposta veio em forma de questão, seguida, novamente, do receio pelo estranho:

Fazer o quê aqui? Ver o quê? Ver quatro pés de beterraba plantada? Não tem condição! A nossa árvore é só aqui... não é muito grande, né, nós que nem, em chácara grande isso aí causa poblema, né, que nem, eles são ricos, né, o cara vem, você atendendo ali, um dia eles vêm e queriam roubar... Esse é o problema, né?! Lá nesse tal de Imbuial, do lado de Santa Gema ali, saindo na 
Tourism in Analysis

rodovia da ribeira, sabe? Por ali teve gente que ficou sem nada, só ficou com a panelinha de cozinhar, fogo, geladeira, tudo que é coisa que tinha. Vai fazer o que com cinco, seis homens num caminhão pra carregar tudo? (Sujeito H)

Entrevistamos um casal de camponeses e perguntamos a eles se eles achavam que o turismo poderia ajudar a melhorar suas vidas. Recebemos a seguinte resposta: “Bem, depende, o setor ajuda, né?! Nós aqui, verdura, vai ajudar o quê?"” (Sujeito I). Essa família se dedica apenas à produção de alface, de todos os tipos, sendo que o forte são as alfaces hidropônicas, produzidas em estufas, as quais são vendidas para o Ceasa. Trata-se de uma propriedade grande e bem cuidada. Algumas de suas filhas moram na mesma propriedade com suas famílias, embora em suas próprias casas. $\mathrm{Na}$ propriedade, havia uma piscina aquecida para adultos e para crianças, um pula-pula e vários brinquedos (balanço, gangorra, entre outros) espalhados pelo jardim, os quais eram, segundo o casal, para seus netos brincarem. As estufas para a produção de alfaces, vistas da casa, ao alto, compunham uma paisagem bem agradável e verde, a qual associada ao silêncio da vida no campo transmitia uma tranquilidade oposta à vida corrida da cidade. Assim, depois de nos dizerem que o turismo não poderia ajudá-los com as verduras, considerando que estávamos ali, em frente às estufas e tudo o mais que já relatamos, dissemos ao casal que os turistas gostariam de visitar a propriedade, afinal, ela era muito bonita. A resposta deles foi enfática: "Vim na minha casa por quê? Buscar o quê? Eles têm a sua casa!” (Sujeito I). Então dissemos que o turista sentaria na grama, traria seus filhos para brincar no pula-pula, afinal eles não tinham aquela tranquilidade na cidade. A resposta veio em tom de brincadeira, mas era sério: "Como diz o caboclo, é das minhas neta, né?" (Sujeito J).

Esse comportamento nos remete à questão da hospitalidade. A hospitalidade e o modo de vida camponeses, ao mesmo tempo que são atrativos para o consumo turístico, podem, contraditoriamente, se colocar como um impedimento para realização desse mesmo turismo pelos camponeses. Isso porque a hospitalidade para o turismo pretende o bom atendimento do sujeito enquanto turista, enquanto consumidor e cliente. Para o camponês, essa hospitalidade engendra outro significado relacionado à outra realidade que faz parte de sua vida cotidiana, intrínseca a seu modo de vida. Trata-se de uma solicitude enquanto um aspecto natural, espontâneo, contudo, para aqueles, que são por eles, conhecidos. Entretanto, gostaríamos de reforçar que essas características fogem a generalizações e são reflexos do que foi apreendido na área de estudo, evidentemente. 
Tourism in Analysis

A exemplo do que estamos dizendo, Paulino (2006) fala sobre a produção de café em uma das unidades camponesas investigadas por ela em sua pesquisa de doutorado:

Não se pode associar o café à propriedade pequena apenas pelo seu caráter comercial. Essa bebida é o símbolo maior da cordialidade camponesa e não aceitá-lo é quase uma indicação de que o visitante não está aberto à reciprocidade. E até no sabor, trata-se de um café diferenciado, pois além do simbolismo, os processos que o envolvem são basicamente artesanais e materializam o trabalho de todos os membros ativos da família (PAULINO, 2006, p. 392)

Essa espontaneidade pode ser facilmente percebida nas palavras de uma camponesa entrevistada. Ao ser questionada sobre a possibilidade de receber turistas em sua casa, ela nos respondeu:

Sei lá, se quiserem vir me visitar, que venham, né?! Mas assim, pra trabalhar, pra apresentar coisas. A gente já tem uma idade que não tem mais vontade, né?! Se tivéssemos os filhos que trabalhassem nisso, tudo bem. Mas os filhos se dispersaram, né?! Saíram pra..., eles estão, pegaram outro ramo. Vidraçaria, esquadria de alumínio e eles estão nisso. E bem que fizeram! Porque lavoura é fogo! Dá muito trabalho e não tem dia santo. Não tem sábado. Não tem chuva. Esses dias de chuva e meu marido, com sessenta e cinco anos, lá na lavoura. Não é fácil! (Sujeito M)

A visitação, para essa camponesa, tinha como significado o indivíduo valorizá-la enquanto pessoa. Visitar como quem se interessa pelo visitado, em uma relação de altruísmo e compadrio. Para o turista, ao contrário, não há vínculos nessa relação que possam ir além da relação cliente-prestador de serviço - isso porque é uma relação pautada no consumo. Ademais, em uma visitação turística, não há tempo disponível para que qualquer relação desse porte seja construída. Na medida em que o turismo vai se desenvolvendo, em qualquer lugar onde ele é implantado, há uma tendência em transformar tudo em mercadoria (CARLOS, 1999). Essa é sua lógica.

Não podemos dizer que não tenha havido tentativas, por parte dos camponeses, em receber turistas. Ao contrário, alguns deles, depois de passarem pela experiência, é que se posicionaram contra a possibilidade de receber turistas, sobretudo em grupos de excursão. Perguntamos a um camponês que passou por essa experiência se em algum momento ele já havia recebido 
Tourism in Analysis

turistas e a resposta dele foi a seguinte: “Já, veio um ônibus aí. Maria Santíssima!”. Sua mãe, que estava próxima de nós enquanto conversávamos, foi logo argumentando:

Se viram loucos aí! Porque só ele e o pai dele né, atender tudo aquela gente. Eles não têm estrutura pra botar toda aquela gente dentro do ônibus, né?! Quando eles chegam assim, eles querem tudo rápido porque o ônibus já vai sair, né?! Aí um queria, outro queria, né?! Se viram loucos, né! (Sujeito N)

E ainda, sobre quantos ônibus eles haviam recebido e a quantidade de turistas, nas palavras desse camponês: “Um só. Tinha quarenta e oito passageiro. Queria entrar tudo dentro da cantina. Nem nós não cabíamos dentro da cantina [risadas]!”. Sobre o que estamos argumentando, outra camponesa também teve algo a nos dizer:

Porque uma vez, veio um pessoal, dois ônibus. Eles não me deram lucro, me deram prejuizo. Eles mexeram por tudo, eles fecharam registro quando eu voltei na estufa estavam os registros todos fechados, as bancadas todas secas, sabe? Pra falar a verdade, não veio uma turma de estudante, veio uma turma de baderneiros, sabe? Eu não sei que turma que era. (Sujeito O)

A camponesa citada acima, além de salvaguardar sua casa de maneira a restringir seu acesso à família, ainda vê na presença turística um elemento que atrapalha sua produção agrícola. Em relação ao outro camponês, perguntamos a ele se não havia interesse, da parte dele, de organizar um colhe-pague, atrativo turístico em que o turista paga pela experiência de colher as verduras do chão e pelas verduras colhidas. Foi essa a resposta dele: "Deus o livre, e pisar na minha lavoura?!" (Sujeito P). Dissemos a ele que havia um sistema de colhe-pague em Colombo e que talvez fosse interessante do ponto de vista da melhoria de seu ganho, mas ele disse que conhecia o dono e a propriedade e que só faz isso quem tem terra sobrando pra criar uma horta com um caminho ao lado, para que o turista possa passar, e outras hortas (que os turistas não tenham acesso), para as necessidades da família.

Esse camponês já tem para quem vender sua produção e não está preocupado em ampliar, em termos mercadológicos, essa produção. Essa atitude, contudo, não está assentada em uma falta de ambição, por assim dizer. O motivo pelo qual ele não tem interesse em ampliar sua produção está assentado em outra questão a qual diz respeito à tradição. 
Tourism in Analysis

Pra nós não tem muito por que entrar no Circuito. Tipo, todo vinho que nós fazemos nós conseguimos vender em casa, sem entrar no Circuito. Então pra nós... Então pra nóis é menos dor de cabeça, assim. (Sujeito P)

Sobre esse assunto, é possível visualizar o valor e o peso da tradição embutida nos afazeres cotidianos quando em sua fala esse camponês afirma não querer ampliar sua produção de uva e vinhos porque está preocupado com a manutenção de sua tradição.

Não. De forma a expulsar esse negócio de artesanal. Nós não somos uma fábrica. Nós não somos fabricante de vinho. Somos produtores de vinho. Nós produzimos a uva e o vinho. Porque dai você vai ter que fazer bastante. Porque a pessoa não pode arriscar, né? Aí você vai ter que entrar, vai ter que entrar com bastante química pra segurar o vinho, quer dizer, vai ter que embalar ele e colocar dentro da parteira, não pode estragar. Não ponhamos nada nele. É do tipo do Nono. Como fazia lá, sessenta anos atrás [risadas]. A uva toda é nossa. Por isso que eu disse pra você: nós somos produtores e não fabricantes. (Sujeito Q)

Por fim, concluímos que vender a própria produção e acumular o valor monetário soa para o camponês como expressão de autonomia. A autonomia tem, ainda, outra dimensão, a qual diz respeito ao controle de seu tempo, como já dissemos. Nesse caso, os camponeses que preferem não se inserir no Citur em virtude da perturbação que o turista pode lhes trazer é um bom exemplo do que pretendemos ilustrar. Para o camponês, a vida que ele levava em sua casa, cuidando de sua lavoura e fazendo de seu tempo o que lhe aprouver.

\section{Considerações finais}

Por tudo o que dissemos, podemos afirmar que, para esses camponeses, a autonomia sobre seu próprio tempo, vida e trabalho agrícola, bem como a manutenção de todos esses fatores, se colocam como impedimentos para a inserção desses camponeses no Citur em Colombo (PR). Para além de uma questão econômica, esses camponeses não estão inseridos no Citur porque não querem estar._Obviamente existem inúmeras iniciativas de turismo que se realiza no campo. No entanto, o objetivo deste trabalho foi apontar a incompatibilidade entre 
turismo e camponês, sob o argumento de que estão situados em tempos e lógicas diferenciadas. $\mathrm{O}$ agricultor familiar, por sua vez, atende aos requisitos para implantação do turismo enquanto atividade econômica. É preciso considerar, no entanto, que existe aí uma especificidade a qual diz respeito a uma lógica nesse agricultor que é contrária à lógica do camponês, enquanto categoria analítica. Sobre esse assunto, discutiremos em outro momento.

Muito embora estejam geograficamente localizados no entorno do Citur, na cidade Colombo, tenham condições econômicas e culturais para isso, porque são todos descendentes de italianos e donos de suas terras e desenvolvem a agricultura como atividade econômica produtiva, o que configura o atrativo turístico. Sua vida cotidiana, no entanto, é pautada em um tempo lento e acontece de maneira diferente da lógica turística, cuja realização está assentada em outras bases, em oposição ao modo de vida camponês, as quais dizem respeito a um tempo rápido, fugaz e superficial pautado em uma relação de consumo.

Dessa forma, consideramos que haja um descompasso entre a produção agrícola, o modo de vida camponês e a lógica do turismo. Embora o turismo possa se colocar como elemento facilitador da venda dos produtos camponeses, já que o turista iria até o camponês comprar seus produtos - até porque esse é um dos discursos sob o qual o turismo realizado em espaço rural está assentado. A possível perda do controle de sua vida em relação ao comportamento do turista, de um lado, e a satisfação em relação à vida que eles já têm, do outro, afirmam suas condições de camponeses não inseridos no Citur em Colombo. Essa perda de autonomia sobre seu próprio tempo tem a ver com a dedicação que o trabalho agrícola exige versus a disponibilidade que o turismo exige enquanto atividade econômica. Tal disponibilidade implica ter que abrir mão das atividades cotidianas relacionadas à lavoura em detrimento do turismo, como pudemos observar nas entrevistas concedidas.

\section{Referências}

BAUDRILLARD, J. Simulacros e simulação. Lisboa: Relógio d’Água, 1991.

CARLOS, A. F. A. O turismo e a produção do não-lugar. In: CARLOS, A. F. A.; YÁSIGI, E.; CRUZ, R. C. A. (Orgs.). Turismo: espaço, paisagem e cultura. 2. ed. São Paulo: Hucitec, 1999. 
Tourism in Analysis

CARNEIRO, M. J. Multifuncionalidade da agricultura e ruralidade: uma abordagem comparativa. In: MOREIRA, R. J.; COSTA, L. F. C. Mundo rural e cultura. Rio de Janeiro: Mauad, 2002.

CHAYANOV, A. V. La organización de la unidad económica campesina. Buenos Aires: Nueva Visión, 1974.

CRUZ, R. C. A. Politica de turismo e território. São Paulo: Contexto, 2001.

LEFEBVRE, H. Perspectivas da sociologia rural. In: MARTINS, J. de S. (Org.). Introdução crítica à sociologia rural. São Paulo: Hucitec, 1981.

LUXEMBURG, R. A acumulação do capital: contribuição ao estudo econômico do imperialismo. 2. ed. São Paulo: Nova Cultural, 1985.

. Introdução à economia política. São Paulo: Martins Fontes, 1969.

MARTINS, J. S. A imigração e crise no Brasil agrário. São Paulo: Pioneira, 1973.

A sociabilidade do homem simples: cotidiano e história na modernidade anômala. 2. ed. São Paulo: Contexto, 2008.

Capitalismo e tradicionalismo. São Paulo: Pioneira, 1975.

. (Org.). Henri Lefebvre e o retorno à dialética. São Paulo: Hucitec, 1996.

. O cativeiro da terra. 8. ed. São Paulo: Hucitec, 2004.

MOURA, M. M. Os herdeiros da terra: parentesco e herança numa área rural. São Paulo: Hucitec, 1978.

ORLANDI, E. P. Análise do discurso: princípios e procedimentos. 5. ed. Campinas: Pontes, 2003.

PAULINO, E. T. Por uma geografia dos camponeses. São Paulo: Unesp, 2006.

SAHLINS, M. O "pessimismo sentimental" e a experiência etnográfica: por que a cultura não é um “objeto" em via de extinção (parte I). Mana, Rio de Janeiro, v. 3, n. 1, abr. 1997. Disponível em: $<$ http://bit.ly/2gMrom9>. acessos em 18 out. 2009.

SANTOS, T. B. B. Turismo e campesinato: embates ideológicos e culturais em Colombo/PR. Tese (Doutorado em Geografia Humana) - Universidade de São Paulo, São Paulo, 2009.

Turismo rural e sustentabilidade: o caso de municípios do Espírito Santo. 2004. 98 f. Dissertação (Mestrado em Ciência Ambiental) - Universidade Federal Fluminense, Niterói, 2004. 
Tourism in Analysis

SILVEIRA, M. A. T. Política de turismo: oportunidades ao desenvolvimento local. In: RODRIGUES, A. B. (Org.). Turismo rural: práticas e perspectivas. 2. ed. São Paulo: Contexto, 2003.

WOORTMANN, E. F. Herdeiros, parentes e compadres: colonos do sul e sitiantes do Nordeste. São Paulo; Brasília, DF: Hucitec; Fundação Universidade de Brasília, 1995.

WOORTMANN, K. "Com parente não se neguceia”: o campesinato como ordem moral. Brasília, DF: Universidade de Brasília; Tempo Brasileiro, 1990.

Recebido em: 16/06/2016 (1 ${ }^{\mathrm{a}}$ versão) $30 / 08 / 2016$ ( $2^{\mathrm{a}}$ versão)

Aprovado em: 19/09/2016 